\title{
MALIGNANT TRANSFORMATION IN A YOUNG ADULT WITH RECURRENT LARYNGEAL PAPILLOMATOSIS
}

\author{
Surg Cdr ARUN BEHLvis ${ }^{*}$, Surg Cdr E JAMES ${ }^{+}$, \\ Dr P KELKAR ${ }^{\sharp}$, Surg Cdr NAVEEN CHAWLA
}

\begin{abstract}
MJAFI 2001; $57: 154-155$
KEY WORDS: Malignant transformation; Recurrent respiratory papillomatosis (RRP); Squamous cell carcinoma (SCC); Tracheo ocsophageal puncture (TEP); Wide field laryngectony.
\end{abstract}

\section{Introduction}

$\mathbf{T}$ he term "papilloma" was first described by Mackenzie in 1880 when he described papillomas in the larynx of a child and used the term 'Juvenile laryngeal papillomatosis'; he also claimed that it was the most benign tumour of the larynx [1].

Human Papilloma Virus (HPV) types 6 and 11 have been associated with recurrent respiratory papillomatosis (RRP). In vicw of the recurrent nature of this condition majority of patients require multiple surgical procedures for tumour removal and maintenance of airway $[2,3]$.

Malignant transformation of RRP is uncommon, however squamous cell carcinoma (SCC) can arise in RRP but is uncommon in the absence of aggravating factors such as tobacco smoking, irradiation and exposure to chemical agents. Genetic mutation of p53 in association with integration of HPV-11 is seen in histologically malignant lesions. This association may promote a progressive genetic instability that can lead to the development and clonal expansion of malignant lesions in RRP [3].

We report a rare case of a 28 year old $\mathrm{JCO}$, nonsmoker, non-irradiated patient who underwent malignant transformation of benign recurrent papillomatosis during LASER treatment. He was treated with wideficld laryngectomy with primary tracheo-oesophageal puncture (TEP) and insertion of PROVOX -2 voice prosthesis for voice restoration.

\section{Case Report}

A 28 year old JCO presented with insidious onset gradually worsening change of voice of $2 \frac{1 / 2}{2}$ years duration. There was no prior history of trauma, fever, dysphagia, haemoptysis, swelling in the neck. anorexia or weight loss. Patient had been treated as a case of acute laryngitis in numerous peripheral hospitals without any significant improvement.

Microlaryngoscopy done showed papillomatous growth involving right vocal cord and anterior $1 / 3^{\text {rd }}$ of left vocal cord. Biopsy from the lesion showed squamous papilloma with dysplastic changes. Before definitive treatment could be started, patient developed severe stridor necessitating an emergency tracheostomy.

The patient then underwent 6 sittings of $\mathrm{CO}_{2}$ laser vaporisation under general anaesthesia at 3 to 4 weeks interval. Serial histopathology reports were consistent with squamous papilloma, however there was no subjective or objective improvement and trial closure of the tracheostomy was not successful.

During the $7^{\text {th }}$ LASER sitting microlaryngoscopy showed extensive papillomatous growth involving right aryepiglottic fold. both false cords and true vocal cords. Subglottic extension could not be seen duc to reduced glottic chink. A biopsy from the lesion showed malignant changes in squamous papilloma. Examination of the neck did not reveal any lymphadenopathy. Fibre optic bronchoscopy done through tracheostomy showed no papiliomas in the lower respiratory tract.

A CT scan showed growth involving both aryepiglottic folds both false cords with subglottic extension. Patient was staged as a case of transglottic Carcinoma Larynx cTMN-T3N0M0.

A wide field total laryngectomy with primary TEP and insertion of PROVOX-2 voice prosthesis was done in this young patient to achieve voice rehabilitation. Postoperative recovery was uneventful with patient able to communicate by the $6^{\text {th }}$ postoperative day.

Final histopathology of the laryngectomy specimen showed supraglottic, glottic and infraglottic regions. Growth was infiltrating right lobe of thyroid. All cut margins were negative. Bilateral pretracheal lymphnode metastasis was detected. pTNM-T4 N2c Mo.

\section{Discussion}

Recurrent respiratory papillomatosis is a benign neoplastic condition characterized by budding tumours developing from endolaryngeal epithelium and involving any part of the respiratory tract [3].

This disease has a strong association with papilloma virus (serotype-6,11,16,18,30). The viral etiology of this condition was first suggested by Ullman in

\footnotetext{
"Classified Specialist (Surgery and Oncosurgery), ${ }^{+}$Classified Specialist (ENT), ${ }^{\#}$ Traince (ENT), ${ }^{* *}$ Classified Specialist (Pathology). INHS Asvini, Colaba, Mumbai - 400005.
} 


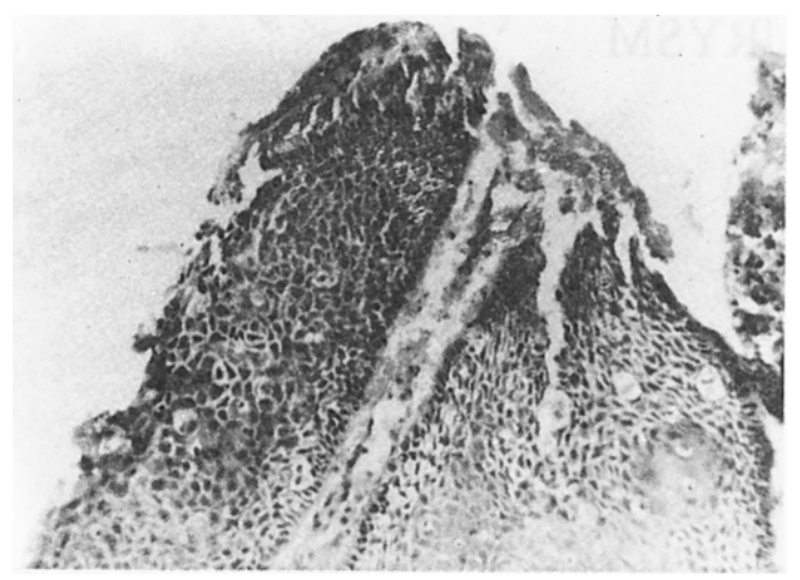

Fig. 1: Squamous papilloma larynx (H and E x 100).

$1928[3,4,6]$.

After infection, the virus may remain in the basal layer of the mucous membrane replicating by a process known as "episomal maintenance" where the virus itself is indetectable and its presence can only be determined by DNA hybridization. Multiple HPV infections can occur in the same lesion. Type 16 and its DNA integration is thought to contribute to the occurrence of severe dysplasia and carcinoma [5].

Recurrent respiratory papillomatosis is more common in the juvenile age group and presents before the age of 4 years. Adolescent and young adults are affected rarely [6]. Initial symptoms include hoarseness of voice. Increasing stridor and acute respiratory obstruction may occur but it is usually a late manifestation and an indicator of conversion to malignancy.

Various modalities have been used in the management of RRP like microscopic removal, $\mathrm{CO}_{2}$ laser vaporisation, interferon therapy and photodynamic therapy. However the lesions are notorious for recurrence even after the most radical extirpation. Standard management currently consists of $\mathrm{CO}_{2}$ laser vaporisation and microsurgical ablation of papillomas $[6,8]$.

Malignant transformation is known to occur in 2$3 \%$ cases especially in the presence of known risk factors such as smoking and irradiation $[1,6,7]$.

Decreased vocal fold mobility, presence of cervical lymph nodes, exuberant and rapid growth, oedema of larynx with airway obstruction, requiring tracheostomy are clinical features suggestive of malignant transformation [6].

Once malignant transformation has occurred laryngectomy is the treatment of choice [9]. Being a young adult in addition to the wide field laryngectomy we did a primary TEP and insertion of PROVOX-2 voice prosthesis to achieve voice rehabilitation with

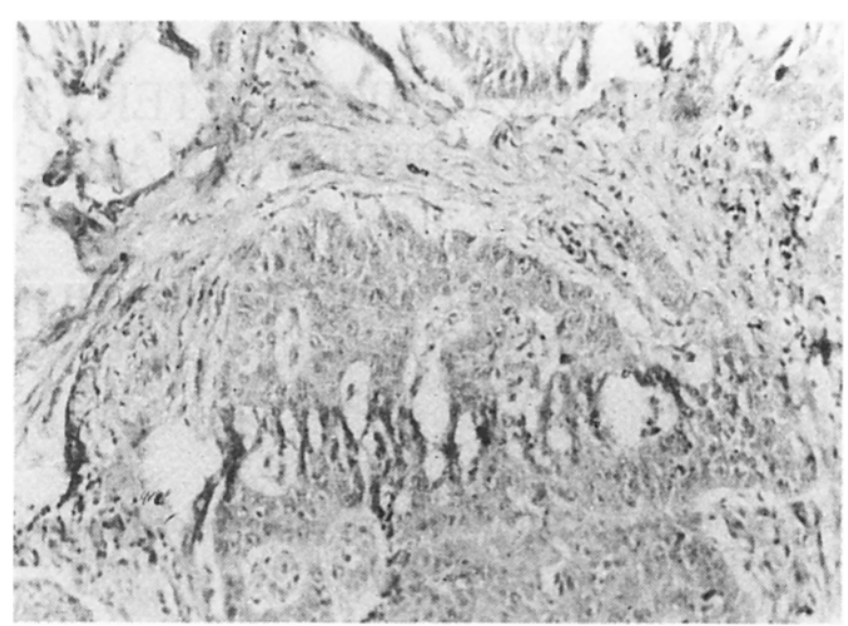

Fig. 2 : Squamous Ca larynx (H and E x 100).

excellent results.

In this case we wish to highlight the rare incidence of squamous papillomas in adults, the need for periodic biopsy and histopathological review and the fact that the rare event of malignant transformation can occur even in the absence of known risk factors like smoking and irradiation.

\section{References}

1. Orphanidou D. Dimakou K, Latsi P, Gaga M, Toumbis M, Rasidakis A, Jordanoglou J. Recurrent respiratory papillomatosis with malignant transformation in a young adult. Respir Med 1996;90(1):53-5.

2. Lin KY, Westra WH, Kashima HK, Mounts P, Wu TC. Coinfection of HPV-11 and HPV-16 in a case of laryngeal squamous papilloma with severe dysplasia. Laryngoscope 1997;107(7):942-7.

3. Rady PL, Sednadig VJ, Weiss RL, Hughes TK, Trying SK. Malignant transformation of recurrent respiratory papillomatosis associated with integrated human papillomavirus type 11 DNA and mutation of p53.Laryngoscope 1998;108(5):735-40.

4. Lindeberg H, Syrjanen S, Karja J, Syrjanen K. Human papillomavirus type 11 DNA in squamous cell carcinoma and preexisting multiple laryngeal papillomas. Acta Otolaryngol (stockh) 1989;107(1-2);141-9.

5. Singh B, Ramsaroop R. Clinical features of malignant transformation in benign laryngeal papillomata. $J$ Laryngol Otol 1994;108(8):642-8.

6. Klozar J, Taudy M, Betka J, Kana R. Laryngeal papillomaprecancerous condition? Acta Otolaryngol Suppl (Stockh) 1997;527:100-2.

7. Healy GB, Gelber RD, Trowbridge AL, Grundfast KM, Ruben RJ, Pice KN. Treatment of recurrent respiratory papillomatosis with human leukocyte interferon. Results of a multicenter randomized clinical trial. N Engl J Med 1988 Aug 18;319(7):401-7.

8. Robbins KT, Howard D. Multiple laryngeal papillomatosis requiring laryngectomy. Arch Otolaryngol 1983 Nov;109(11):765-9. 